\title{
Uma facada pelas costas: paranoia e Teoria da Conspiração entre conservadores no refluxo das Greves de 1917 na Alemanha
}

\author{
A Stab in the Back: Paranoia and Conspiracy Theory among \\ Conservatives in the Undertow of 1917 Strikes in Germany
}

Vinícius Liebel*

\section{RESUMO}

Este ensaio analisa as discussões políticas e o imaginário alemão relativos ao movimento pela paz e às grandes greves na Alemanha em 1917 e 1918, refletindo sobre a transformação de suas significações políticas no imediato pós-guerra, em particular nos círculos conservadores. Esses eventos se conformam em gatilhos para uma onda paranoica que varreu a política alemã nos anos seguintes, possibilitando a ascensão de grupos conservadores e extremistas, dentre eles o Partido Nazista. O texto, assim, se divide em três partes: uma breve incursão sobre o conceito de paranoia e seus desdobramentos; algumas considerações sobre a paranoia e a teoria da conspiração no imaginário e nos espaços sociais conservadores; uma análise do mito da facada pelas costas, grande narrativa conspiratória do período, considerando suas influências na disseminação do antissemitismo e do ódio aos "inimigos internos", essenciais na estratégia discursiva nacional-socialista.

Palavras-chave: paranoia; Teoria da Conspiração; nazismo.

\section{Abstract}

This paper is focused on the political debates and the German imaginary concerning the peace movement and the major German strikes in 1917 and 1918, reflecting about the transformation of its political significance in the immediate postwar period, particularly in conservative circles. These events turn into triggers for a paranoid wave that dominated German politics in the following years, enabling the rise of conservative and extremist groups, the Nazi Party among them. The article is divided in three parts: (1) a brief overview of the concept of paranoia; (2) some considerations about the relation between paranoia and conspiracy theory in the imaginary and in the conservative social spaces; (3) an empirical analysis of the myth of the "stab in the back", the great conspiratorial narrative of the period, considering its influences in the spreading of antiSemitism and hatred against the "internal enemies", an essential feature of the national-socialist discursive strategy. Keywords: paranoia; Conspiracy Theory; Nazism.

\footnotetext{
* Pós-doutorando no PPG-História da Universidade Federal Fluminense, pesquisador associado ao Núcleo de Estudos Contemporâneos (NEC-UFF) e ao Núcleo Interdisciplinar de Estudos Judaicos e Árabes (NIEJ-UFRJ).v_liebel@yahoo.de
} 
Em uma das obras mais aclamadas da literatura mundial, Shakespeare compõe um cenário de intrigas e ilusões no qual o personagem central, Otelo, irá se enredar, acabando por enlouquecer e assassinando sua amada Desdêmona. A trama de Otelo se centra em quatro personagens principais: Otelo, um comandante mouro das tropas venezianas; Iago, seu conselheiro; Cássio, seu braço-direito, e Desdêmona, sua esposa. A união de Otelo e Desdêmona acontece em segredo, uma vez que o pai da jovem, Brabantio, esperava que ela se casasse com um senador da República. Agente ativo nessa união secreta, Cássio, soldado de Otelo, recebe como recompensa a promoção ao posto de tenente. Esse é o estopim para que Iago, alferes e conselheiro de Otelo, passe a planejar sua vingança, uma vez que foi passado para trás na fila da promoção. A estratégia que Iago utilizará será a semeadura do ciúme e da desconfiança de Otelo em relação a Desdêmona e Cássio. Mediante uma série de subterfúgios, Iago mostra a Otelo os caminhos da traição dos dois, o que, ao final, acaba por consumir completamente a mente do comandante mouro. Otelo entra em um círculo paranoico que o leva às raias da loucura, terminando por assassinar sua esposa convencido de que ela o traíra. A ama de Desdêmona, esposa de Iago, ao ver o corpo sem vida, explica a Otelo toda a trama, levando-o ao desespero e ao suicídio.

A paranoia de Otelo é um caso individual, extremo e minuciosamente planejado por seu alferes. Ela é alimentada pelo ciúme, pela luxúria e, também, pela quebra da autoimagem, pelo esfacelamento do orgulho do macho-alfa. A espiral psicológica que envolve o herói mouro shakespeariano e o leva à sandice tem forte conotação sexual. Mas esse não é um elemento fundador da paranoia, em especial quando a pensamos em sua natureza coletiva. Nesse caso, o sentimento de paranoia pode romper a barreira do indivíduo e se tornar um elemento político-social determinante em certos contextos. A paranoia coletiva, em conjunturas específicas, passa a guiar ações e pensamentos em direção ao caos e à irracionalidade. Ela se torna, assim, o motor que faz as engrenagens da ação social e da (anti)lógica da arena pública girarem.

O contexto do final da Primeira Guerra Mundial, quando os países beligerantes - na Europa e além - são tomados por greves, manifestações e pelas notícias da eclosão da Revolução Russa, demarca um novo momento para a história política. Nele o acirramento da contraposição entre esquerda e direita, progressistas e conservadores é elevado a um novo patamar, e um imaginário de medo e desconfiança é reforçado, pautado pelas representações do perigo comunista, pela névoa das teorias da conspiração e pela constante presença da paranoia. A instabilidade abissal daquele momento gerou o ambiente propício 
para o desenvolvimento dessa dinâmica, que viria a delinear boa parte dos discursos e das ações políticas na Europa, mas particularmente na Alemanha, nos anos seguintes. Os fantasmas que povoavam o imaginário alemão do período transformaram boa parte da população em Otelos, e a dinâmica política que se seguiu resultou, também, em assassinato. A paranoia ganha assim em importância política e histórica, mostrando-se um fenômeno determinante em dados contextos. Nas próximas páginas serão apresentadas algumas considerações sobre a paranoia e as teorias da conspiração, elementos ativos na política da Alemanha de Weimar. Algumas reflexões sobre o lugar da paranoia no discurso e na construção da história daquele contexto serão tecidas, para, em seguida, ser apresentado um estudo de caso, centrado no mito da "Facada pelas Costas".

\section{PARANOIA}

A paranoia está frequentemente vinculada a uma teoria, a uma ideia pré-formada, a um engendramento quase lógico que resulta em um evento catastrófico, em um ataque ao status quo ou, em linhas gerais, em uma traição, como a infidelidade de Desdêmona. De fato, todo pensamento paranoico tende a ser aparentemente bastante lógico, mas tende também a se basear em uma falácia, ou seja, todo o edifício lógico e de causas e consequências acaba se sustentando em areia movediça. Mas se a paranoia é um estado tão fora da curva como se alega, como ela surge tão frequentemente e, principalmente, como pode a história dar testemunho de tantos casos de paranoia coletiva?

Uma explicação que surge se respalda na teoria da psicanalista ${ }^{1}$ Melanie Klein (1997). Tomando os casos infantis como base para suas pesquisas, a austríaca percebe, ao contrário de Freud, que o ego não é uma estrutura fechada e inerente ao ser, mas se forma na primeira infância em diferentes estágios, e depende fundamentalmente dos estímulos internos e externos. Nascem dessas teorias as ideias de potencialização de personalidades tirânicas a partir de infâncias frias e conflituosas. Seria a busca constante pelo controle e destruição das fontes potenciais de sofrimento e de prazer que levariam a uma tendência destrutiva e autoritária.

No que se refere à paranoia, sua teoria se baseia, em primeiro lugar, no que ela chama de ansiedade paranoide, gerada pelas frustrações do ambiente e percebida como uma persecução constante. O ego em formação e ainda estilhaçado passa a associar suas frustrações externas com seu objeto primordial, o seio materno, o "objeto mau" (ou inimigo) que o faz sofrer pelas privações e 
o persegue. Ele demonstra ter "medo da aniquilação, que retorna como perseguição por parte de um objeto ao qual sua angústia se apega, um objeto incontrolável e poderoso" (Kristeva, 2001, p.60). Essa ansiedade é extrapolada de forma violenta com choros, arranhões e mordidas no seio, por exemplo, pois ele é o centro de sua vida, compreendido como fonte de todo bem e de todo mal vivenciado. Entretanto, ainda no primeiro ano de vida essa ansiedade começa a regredir, a criança diferencia os objetos externos de seus sentimentos e imagens internas e reprime suas manifestações instintivas. A perseguição não é mais sentida, ou ao menos não é mais uma constante traduzida na agressão. Esse é o princípio da manifestação da culpa e do desenvolvimento da responsabilidade, e a criança começa a perceber sua posição de intermediador da fúria interna para a agressão externalizada.

Klein denomina esses estágios de posições psicológicas, o que implica a possibilidade de retorno, ou seja, uma superação momentânea (que pode se estender para toda a vida) dessa ansiedade paranoide. Entretanto, essa potencialidade da posição permanece uma constante na vida do adulto. Como caracteriza Luigi Zoja,

circunstâncias violentas, parecidas com as que nos eram intoleráveis na primeira infância, podem reativar atitudes esquizo-paranoides. Quando isso acontece, o sujeito se mostra agressivo, e como tem dificuldades para assumir a responsabilidade de um modo pessoal, projeta todo o mal sobre os demais. ... [ou seja], há um potencial paranoico presente em todo homem comum, em todas as fases de sua existência, e qualquer que seja a sociedade na qual ele viva. E o ambiente que o cerca tem o poder de ativá-lo. (Zoja, 2013, p.30-31, trad. nossa)

A paranoia, portanto, tem a potencialidade de se manifestar em qualquer pessoa e em qualquer momento, basta para isso que o gatilho necessário seja apertado. Problemas com a autoridade, frustrações humilhantes, ameaça de rompimento com os laços que determinam sua identidade, enfim, eventos que modifiquem ou ameacem modificar sua estabilidade levam o indivíduo a projetar no próximo sua agressividade em relação à sua situação. Ao mesmo tempo, podem gerar uma condição de ansiedade em relação ao ambiente e aos semelhantes, criando uma permanente sensação de perseguição e de observação no indivíduo. Ao abordar a questão da autoridade na obra de Klein, John Phillips descreve que "todas as relações, seja entre o ego e seus objetos ou entre os próprios objetos, são consideradas em termos de uma violência que tem sua manifestação primária na fantasia infantil. A violência da fantasia transforma 
o exterior pela absorção" (Phillips, 1998, p.159). Alguns exemplos banais: o ladrão que se sente permanentemente vigiado, o indivíduo que reprime seu desejo com medo das repercussões sociais e se torna ansioso, o funcionário incompetente que tem medo da autoridade onipresente do patrão e do escrutínio público; todos eles vivem em ambientes primariamente fantasiosos e inóspitos, em "situações limítrofes", e são potencialmente paranoicos. As condições para que a paranoia surja dependem do indivíduo, de sua infância e sua estabilidade, mas, ao fim e ao cabo, ela é compreendida como potencialidade universal.

Essa potencialidade está presente também quando o indivíduo deixa o âmbito privado e adentra a esfera pública. Uma vez em grupo, e dependendo do ambiente, a unidade do coletivo pode agir na potencialização dessa ansiedade. Mais do que isso, a falta de unidade das massas, a capacidade que elas têm de atrair elementos das mais diferentes origens, dilui a identidade individual e a deixa mais sujeita às variações do ambiente.

Duas questões precisam ser reforçadas a esse respeito. A primeira é a de que a paranoia não ocorre em um indivíduo isolado; trata-se de uma condição inerentemente social, ou seja, na projeção psicológica, isto é, imaginária da sociedade. Mesmo um ermitão que passe a desenvolver um pensamento paranoico o faz por sua percepção social, ou seja, por se compreender em uma sociedade e se sentir, de alguma forma, inserido nela - o que viabiliza a ansiedade persecutória. A segunda questão se refere à violência inerente ao processo, não só na possibilidade de extravasamento por parte do paranoico, mas também pela condição que está em geral relacionada ao gatilho. $\mathrm{O}$ ambiente que o envolve demonstra certa dose de violência, seja ela física, psicológica ou discursiva. Mesmo que essa violência não seja direcionada diretamente ao paranoico, ele a perceberá como tal e, assim, agirá em conformidade. Para o paranoico, qualquer violência que parta de si é justificada como uma autodefesa. Isso se verifica tanto em atores individuais quanto em atores coletivos ou institucionais. Apenas a título de exemplo, em alguns dos documentos secretos da CIA recentemente liberados, fica evidente a compreensão da agência norte-americana de que o AI-5 brasileiro foi decretado por conta de um clima paranoico que dominou tanto atores individuais (como o próprio Costa e Silva) quanto o ator institucional do Exército (Rocha, 2016). Atores em estado paranoico tendem a cometer ações extremas e tomar decisões emocionais de rompante.

$\mathrm{Na}$ coletividade, entretanto, a ativação de paixões coletivas se exponencializa. Em grupo, na massa, a percepção da violência enquanto ato transgressor e 
a possibilidade de remorso (como ocorre no caso de Otelo, que se suicida sobre o corpo de Desdêmona após perceber seu erro), ou seja, esse lampejo de racionalidade e de arrependimento, praticamente inexiste, pois na massa os impulsos de destruição se normalizam - não há espaço para sentimentalismos (Canetti, 1995). No desenvolvimento da ansiedade paranoide coletiva, o indivíduo se perde nas paixões públicas e os atos de violência e as agressões se propagam como ondas autojustificadas.

Se a violência se normaliza e o indivíduo tem sua identidade diluída na massa, passa a ser coerente a compreensão da paranoia coletiva como um desdobramento possível e razoavelmente regular na história moderna e contemporânea. Mais ainda, passamos a compreender o grau de violência que muitas vezes reconhecemos em movimentos políticos contemporâneos. Impossível não reconhecer a validade da teoria de Chantal Mouffe (2005) acerca do político enquanto campo de confrontação de adversários ${ }^{2}$ e perceber o papel que a paranoia e as teorias de conspiração assumem nesse espaço. $\mathrm{O}$ reflexo da imagem paranoica é sempre a construção de um inimigo, não de um adversário, e o uso da violência se normaliza quando tratamos de inimigos, não apenas no campo discursivo, mas no campo da realidade física. O campo do político de Mouffe pressupõe a revitalização do emocional, mas não deixa de ser racional. No disparo de uma paranoia, o racional é dominado pelo emocional. Não quer dizer que não exista lógica na construção narrativa dos paranoicos, mas, como afirmei há pouco, essa lógica segue uma lógica própria, falaciosa, independente da realidade.

\section{Conservadorismo e Paranoia}

Partindo para uma análise mais específica, centrada na relação entre o conservadorismo e a paranoia, é necessário levantar alguns pontos. Não se trata de caracterizar a paranoia, no campo político, como um traço exclusivo dos conservadores ou dos movimentos de direita. Como já exposto, todos têm em si a possibilidade de sofrer alguma forma de distúrbio paranoico. Entretanto, uma observação histórica do lugar da paranoia e das teorias da conspiração no campo político acaba destacando que momentos e movimentos conservadores em crise tendem a ser mais propensos a gerar o ambiente necessário para difusão da visão paranoica e para a formulação de teorias conspiratórias. Alguns casos de paranoias coletivas geradas na era contemporânea ajudam a visualizar esse argumento, como o caso da "Conjuração dos Filósofos", ${ }^{3}$ disseminada entre parte da elite nobiliárquica e religiosa europeia 
sob a sombra da Revolução Francesa; ou a ideia de que a Maçonaria e os illuminati serviam como agentes de Napoleão na conquista dos Estados alemães; ou ainda a imagem da conspiração bolchevique que perpassou praticamente todo o século XX, transformando os comunistas nos agentes de ações secretas em todo o Ocidente.

Trata-se, aqui, do campo do político e da política em termos estritamente coletivos, ou seja, em movimentos, partidos, grupos ou coletividades que operam na arena pública. Em graus extremos, podemos falar de massas. Quanto maior o número de membros dessas coletividades, maior será a supressão da lógica e da moral. Em um ambiente onde um ator excita o outro com palavras de ordem, gestos ou com a simples presença, o discurso rapidamente regride ao campo da amoralidade, do escatológico e da pornografia.

Nesses fenômenos coletivos, o gatilho não ocorre apenas por um evento significativo. De fato, mesmo quando há esse evento, ele não necessariamente conduz as massas ao estágio paranoico de ansiedade. Apenas como exemplo, o evento da Revolução Francesa serviu como gatilho para o pensamento conservador antirrevolucionário e anti-iluminista gerar a imagem de uma grande conspiração secreta envolvendo satanistas, maçons, illuminati e outros grupos menores contra deus, o rei e a tradição (Bieberstein, 2008, p.40ss). Os escritos de Augustin Barruel (1797/1798) são o que há de mais exemplar nesse assunto.

Não é, portanto, o mero evento que irrompe a sanha paranoica. Para que ela se desenvolva, é necessário que o ambiente se torne propício e que haja uma continuidade na manutenção dessa aura. É necessário que o momentum seja conduzido pelo medo, pela ansiedade e pela desconfiança. Isso depende, é claro, da comunidade em questão e de sua temporalidade. Em Salem, por exemplo, a paranoia e a histeria se espalharam pelos relatos e testemunhos no tribunal, nas conversas e nos sermões na igreja. Uma comunidade diminuta, baseada em uma sociabilidade pessoalizada, centrada na igreja e com um universo de menos de 600 habitantes não precisa de mais do que o boca a boca para criar um ambiente paranoico, orientado pelo terror de um discurso dogmático e opressor provindo de uma autoridade institucional baseada em mitologias totalizantes e maniqueístas: a Igreja.

Porém, quanto maior for o espaço geográfico, o universo de potenciais paranoicos e a diversidade dos indivíduos, mais complexa é a estrutura do gatilho. Em nossas sociedades contemporâneas, a eficácia dos meios de comunicação e de propaganda é central nesse processo. Ansiedade, terror e pânico, assim como calma e tranquilidade, podem ser despertados com um simples programa de rádio, como Orson Welles já demonstrou. Assim sendo, a teórica 
dificuldade em se alcançar o ambiente de ansiedade paranoica é, na verdade, facilitada pela técnica, dependendo apenas da intenção, do mau uso ou da irresponsabilidade dos meios de massa. Uma notícia, a insistência na exposição de uma situação alarmante fictícia, ou ainda a criação de um inimigo coletivo costumam estar no princípio de um surto paranoico coletivo.

A eleição de um inimigo, a narrativa de um complô, a conspiração pelo poder mundial; todas essas estratégias imaginárias visam provocar o medo da mudança. Em outras palavras, a narrativa da conspiração se pronuncia contra os instintos conservativos. Em praticamente todos os ambientes paranoicos, a mensagem subliminar que domina as mentes é aquela da mudança de seus modos de vida e do medo que ela traz. A vida nunca mais será a mesma depois do desastre referido, e quaisquer que sejam sua posição, seu status ou seus privilégios, eles serão retirados. No Ocidente, uma longa lista de inimigos cobre essa prerrogativa: maçons, illuminati, opus dei, jesuítas, bolcheviques, socialistas e social-democratas já tiveram cada um o seu momento - ou momentos. Nenhum deles se compara, entretanto, ao inimigo imaginário judeu. Esses elementos costumam estar ligados a pelo menos uma de duas características: por um lado, são relacionados com políticas e ideias liberais, progressistas e/ou revolucionárias; por outro são elementos supranacionais, com possibilidades de deslocamentos transnacionais e voltados a objetivos internacionalistas. Opõem-se, assim, ao conservadorismo, ao nacionalismo, ao status quo. É natural, portanto, que o ambiente de ansiedade paranoica atinja primariamente aqueles que têm (ou acreditam ter) algo a perder com a ação desses elementos - ou de seus correlatos.

Theodor Adorno (1995) identificou alguns elementos da produção desse ambiente de ansiedade paranoica como intrínsecos ao caráter autoritário. Em primeiro lugar, o discurso autoritário conservador tende a denunciar a "perseguição dos inocentes” (p.369-371). Esse princípio permite que o emissor da mensagem torne-se o grande intérprete de toda e qualquer ameaça que seu público sofra ou imagine sofrer. Por sua vez, o princípio persecutório autoriza a racionalização de qualquer agressão como autodefesa, agressão que se naturaliza nas massas.

O segundo elemento descrito por Adorno (1995, p.371-372) é a infadigabilidade (Unermüdlichkeit), traduzida como a necessidade de resistir a essas ameaças de forma incessante. $\mathrm{O}$ inimigo não dorme, proclama esse princípio, ele maquina sua ascensão para tomar seu lugar neste exato instante. $\mathrm{O}$ medo, a constante ameaça (real ou imaginária), proclama que os inimigos devem ser combatidos incessantemente, e que toda oportunidade para desmascará-los 
deve ser aproveitada. No sistema ideológico nazista, na Alemanha dos anos 1920 e 1930, isso se respondia com trabalho ininterrupto em favor do partido e do Estado, com a conversa "esclarecedora" com seus vizinhos ou familiares. Na prática, essa reação servia a uma propagação e manutenção de um ambiente em perpétua ansiedade, o terreno propício para, mais uma vez de acordo com Melanie Klein, o surgimento de um pensamento paranoico (Klein, 1960, p.228-233).

Por fim, Adorno (1995, p.375-381) reconhece um princípio esquizofrênico na construção da autoimagem do líder e de sua potência na denúncia desses inimigos. Caracterizado pelo frankfurtiano como a imagem do grande pequeno homem (grosser kleiner Mann), trata-se da projeção dos mesmos medos e das mesmas ansiedades que o público sofre na persona do líder. Dessa forma, a totalidade do ambiente se mostra abarcada pela paranoia, uma vez que mesmo seu principal líder também se encontra sob a pressão que o ambiente carregado de ansiedade paranoica exerce. Um misto de empatia e projeção verifica-se na relação líder/seguidor. Concomitantemente, essa deferência pela liderança ganha o reforço da gratidão pela denúncia do inimigo/complô e pelo carregamento do fardo de guiar os justos na luta contra os maus. Toda a megalomania que se verifica na retórica do líder inflama e é transferida também para o receptor. Aqueles seres diminutos, com medo e retraídos por conta do inimigo, se engrandecem no embalo da retórica de seu líder. Essa dicotomia entre a autoimagem de seres simultaneamente minúsculos e gigantes está no cerne da recomposição do ego dessas pessoas, que havia voltado a se sentir quebradiço e ameaçado, da mesma forma que um recém-nascido.

Na visão de mundo dos conservadores, fica evidente a ameaça constante de elementos externos e internos à sua posição. E essa assertiva é corroborada por estudos em Psicologia e Biologia políticas (Hibbing; Smith; Alford, 2014; Lodge; Taber, 2013). Experiências nesses campos mostram não só que a resposta automatizada e as reações emotivas são orientadas por respostas preconcebidas e por predisposições emocionais (ou seja, em temas políticos, as reflexões são imediatamente eliminadas em prol de respostas prontas e imagens preexistentes e, assim, o preconceito político se torna uma característica quase natural do debate). Mostram também - e isso é para nós mais importante - que pessoas que se consideram conservadoras enxergam o mundo de uma forma mais ameaçadora (Hibbing; Smith; Alford, 2014). Isso faz que a tendência, em casos mais extremos, seja muito maior de conservadores entrarem em um círculo paranoide e sucumbirem a teorias da conspiração do que liberais e progressistas. ${ }^{4}$ Em outras palavras, conservadores tendem a preservar 
sua identidade de grupo ou o status quo da sociedade de forma mais espontânea, e, assim, estão mais sujeitos, diante de uma ameaça possível (ou imaginária), a embarcar em uma onda paranoica.

Conjugam-se, no caminho para a paranoia, as experiências de frustração e de impotência (Funke, 2002, p.12), ou seja, é na percepção das mudanças sociais, de crises e de sua própria estagnação ou retrocesso que o ambiente paranoide se estrutura. Se o mundo parece progredir e o conservador se sente estagnado, é natural que se sinta também ameaçado pela evolução dos demais. Trata-se da desordem no mundo; um mundo que se julgava estruturado parece cair em ruínas, e o caos que parece se instaurar não pode ser benéfico nem pode ser fruto da inércia ou da incompetência do conservador. É preciso encontrar alguma outra explicação, e nesse processo a ansiedade que o ambiente fomenta transforma-se facilmente em medo. Isso porque a diferença entre os dois sentimentos reside justamente na fonte de sua causa: sendo ela conhecida, tem-se o medo, senão a ansiedade. $O$ processo de produção de um bode expiatório, de uma narrativa que imputa a outrem o protagonismo da ameaça, retira o elemento desconhecido da equação e possibilita que o indivíduo ou o grupo possa focar na defesa contra esse inimigo alvejado. A paranoia então deixa de ser acompanhada de uma ansiedade e passa a coexistir com o medo e, em geral, o ódio. Como descreve Joanna Bourke,

na negociação entre o indivíduo e o grupo social, a diferença entre medo e ansiedade oscila dramaticamente. No tempo histórico, ansiedade é facilmente convertida em medo, e vice-versa. A incerteza da ansiedade pode ser abolida no processo de determinação de um inimigo (sendo esse um inimigo plausível ou não), convertendo ansiedade em medo ... Também tem uma função política: um bode expiatório, por exemplo, possibilita que um grupo converta a ansiedade em medo, influenciando assim (por exemplo) as preferências de voto contra um grupo 'outsider'. (Bourke, 2005, p.190)

As narrativas conspiratórias surgem então para sustentar essa percepção e encontrar o bode expiatório necessário para aliviar sua frustração. Ainda que falaciosa, a narrativa da teoria da conspiração, fruto da paranoia, ganha em importância histórica ao adentrar a arena pública e se mostrar relevante para os desenvolvimentos políticos. Quando ganham as massas, a teoria e a paranoia são responsáveis por encaminhamentos práticos determinantes. Trata-se, ao fim, dos resultados de uma crença, de uma ilusão. O ensinamento de Freud (2006) aqui se aplica: ao crente não adianta explicar racionalmente as falhas 
de sua crença, ele não deixará de acreditar, pois além de parte de sua identidade, a crença é também parte de sua força e segurança psicológica. Diante de potenciais ou reais mudanças na realidade política, econômica e social, uma realidade psicológica é construída para justificar sua própria situação, possivelmente deteriorada, na nova realidade. $O$ paranoico se exime assim de qualquer responsabilidade, e naturaliza-se a violência contra o novo inimigo como alternativa para resolução. Isso se mostra ainda mais eficaz quando o espelho da coletividade parece refletir seu pensamento e sua percepção. Tudo volta a fazer sentido, o mundo está de ponta-cabeça por culpa do outro. O inferno são sempre os outros.

\section{Estudo de Caso - A Punhalada pelas Costas}

Conjunturas de crise se tornam, portanto, o momento propício para o gatilho de uma crise paranoide coletiva. A mudança ocasionada pela Primeira Guerra Mundial no continente europeu certamente conta entre as mais agudas da história. A ordem da "velha Europa", suas tradições e instituições ruíram a passos largos no decorrer do conflito, mas encontraram no ano de 1917 o ponto de virada para a decaída final. Na Alemanha, a situação era ainda mais estranha. As tropas alemãs se encontravam no interior do território francês, mas o princípio da Guerra Total $^{5}$ e a ditadura implantada pela cúpula do Exército, em particular pelo marechal Hindenburg e pelo general Ludendorff, acabaram cobrando um preço muito alto da população. O resultado foi o surgimento de um movimento massivo de protestos contra a guerra e contra o império, vinculado em larga medida à esquerda - particularmente aos social-democratas, mas não só a eles - e que teve a capacidade de organizar grandes parcelas dos trabalhadores em duas greves de alcance nacional: uma em abril de 1917 e outra em janeiro de 1918.

Essas greves, junto à opinião pública no país e à desmoralização dos soldados nas trincheiras provocada pela crise interna, acabaram mostrando-se determinantes para a capitulação alemã. Suas motivações eram bastante claras: apesar de os exércitos manterem uma posição de aparente superioridade no front de batalha, as condições para sobrevivência no interior do Reich se degradavam dia a dia. Entre as principais denúncias dos grevistas estavam a falta de alimentos e o fim das reservas de carvão e de energia. Figuras emblemáticas da esquerda alemã, como Rosa Luxemburgo e Karl Liebknecht, ganham projeção nesses movimentos e se tornam líderes de uma ala mais radical do movimento social-democrata, a Liga Espartaquista (Spartakusbund). Apenas em 
Berlim, a greve de janeiro de 1918 contou com mais de 400 mil participantes (Nebelin, 2010, p.273), interrompendo a produção de produtos essenciais para a manutenção dos exércitos e impondo o fim de qualquer pretensão da elite alemã em continuar com o conflito.

O que se seguiu foi uma sequência de pressões e movimentos políticos que culminou com as reformas de outubro de 1918, nas quais as estruturas do Estado monárquico abriram espaço para uma "parlamentarização" (Schulz, 1969, p.133) do regime, preparando assim a Alemanha para o sistema republicano. As reformas garantiram também uma anistia geral para os presos políticos, entre eles Rosa Luxemburgo e Karl Liebknecht. O mês seguinte viu a abdicação do Kaiser, a assinatura da capitulação alemã e a eclosão da revolução de novembro, que teve como alguns dos atores principais a Liga Espartaquista e o Partido Comunista, fundado em dezembro. O levante se espelhava na Revolução Russa, pretendendo destituir toda a elite aristocrática e burguesa que os arranjos pela instituição da República (liderados pelo Partido Social-Democrata) haviam mantido no poder. As greves e os discursos foram reprimidos com violência; seus principais líderes, entre eles Rosa Luxemburgo e Liebknecht, foram assassinados, e a República de Weimar foi finalmente inaugurada em agosto de 1919, com a promulgação de sua Constituição. Em meio às múltiplas crises - econômica, política, institucional -, os fantasmas da esquerda radical continuaram a habitar o país, reforçados pelo medo dos vizinhos bolcheviques.

Essa conjuntura de instabilidades e de ameaça constante à ordem e à tradição produziu um imaginário fragilizado e povoado por imagens de violência. Impossível não pensar em uma correspondência entre a teoria de Melanie Klein e a identidade estilhaçada dos alemães do pós-guerra. O ambiente de constante ansiedade que se verifica torna-se campo fértil para o surgimento da paranoia e de teorias da conspiração. Não por acaso, uma das principais narrativas conspiratórias que surgem nesse período tem relação direta com um dos responsáveis pelos últimos anos da Alemanha pré-republicana, o general Ludendorff:

Um dia, ao visitar Ludendorff, o General Sir Neill Malcom, chefe da Missão Militar britânica, surpreendeu-se ao ouvir que o Exército jamais teria perdido a guerra se não fossem as vacilações e a fraqueza do povo e do Governo alemães, que, disse Ludendorff, se haviam revelado indignos dos guerreiros seus antepassados. Ludendorff não estava sendo muito coerente, e o General Malcom, para fixar-lhe o argumento, perguntou-lhe: "O senhor está querendo dizer, General, 
que foi apunhalado pelas costas?". Os proeminentes olhos azuis de Ludendorff iluminaram-se com a frase. “É isto!", exclamou triunfante. “Apunhalaram-me pelas costas! Apunhalaram-me pelas costas!” (Goodspeed, 1968, p.299)

Essa conversa, que ganhou aura lendária nas décadas seguintes ao final da Grande Guerra, é ainda hoje objeto de controvérsias entre os historiadores. Sua veracidade já foi colocada em xeque algumas vezes, ${ }^{6}$ bem como a identidade do general que teria conversado com Ludendorff no Hotel Adlon, em Berlim, quando do regresso do líder militar alemão após curto período de exílio na Suécia. Entretanto, a correspondência factual dessa conversa com a realidade pouco importa. O que importa aqui é o sentido histórico que ela assume no período.

A ideia central da conversa aqui descrita é a de que a Alemanha não teria perdido a guerra se não tivesse sofrido com as agitações políticas e militares na sua retaguarda, ou melhor, no seu próprio interior. Ao esgotamento do exército no front se juntavam a fome e a miséria no interior do país, possibilitando a ascensão de um movimento revolucionário que, entre marchas e contramarchas, levou à queda da monarquia e ao estabelecimento de uma república parlamentar. A partir do movimento revolucionário de novembro - e da queda do movimento espartaquista - o Partido Social-Democrata (SPD) surge como principal ator político na nova Alemanha, e com os partidos de Centro (Zentrum) e o Partido Democrata Alemão (DDP) acaba formando uma coalisão de defesa da Constituição de Weimar. O sistema democrático e liberal, entretanto, abrigava também as agremiações que contestavam essa nova ordem, em especial o Partido Comunista (KPD) e os pequenos partidos de natureza völkisch, dentre os quais se destacam o Partido Nacional Popular Alemão (DNVP), de caráter monárquico, e o NSDAP, o Partido Nazista.

Para boa parte da população alemã, o que se via com essa nova configuração política era um confuso mosaico de ideologias, de visões de mundo e de organizações partidárias que lutavam, muitas vezes fisicamente, pela hegemonia no novo sistema. Em suma, a derrota na Grande Guerra parecia ter trazido o caos para a política nacional, o que, aliado à crise econômica e ao alijamento do Exército provocado pelo Tratado de Versalhes, deixava pouco espaço para o conformismo. A arena pública teve ainda o reforço da produção historiográfica imediata, da Zeitgeschichte e das memórias no momento imediatamente posterior à repressão das agitações. As primeiras obras sobre as greves e a revolução que a segue surgem já na década de 1920, com o calor da luta fratricida ainda pulsando entre os cronistas e historiadores. Uma interpretação que se tornou 
hegemônica nos primeiros anos aponta para a luta dos social-democratas contra a bolchevização do país, buscando romper o ciclo de influências que os espartaquistas vinham acumulando após as greves. Phillip Scheidemann, líder do SPD e "segundo proclamador da República" - o primeiro havia sido Liebknecht no mesmo dia -, sublinha em suas memórias o caráter ideológico do confronto: "Eu vi a loucura russa em minha frente, a substituição da dominação do medo czarista através de uma outra, bolchevista. Não! Não! Não na Alemanha, depois de todas as outras misérias" (Scheidemann, 1928, p.310).

As razões para essa construção narrativa se centrar em um modelo de cruzada contra os espartaquistas/bolchevistas e não em uma mera luta pela hegemonia do poder em um país em crise tem ainda relação com concepções prévias que envolviam a ideia de corpo nacional e a contraposição entre reformistas e revolucionários. $\mathrm{Na}$ esteira desses debates, a própria entrada da Alemanha na Primeira Guerra ${ }^{7}$ se torna objeto de discussão. Enquanto, de forma geral, reformistas concebiam o conflito como uma guerra de defesa na qual o Império Alemão teria sido forçado a entrar, entre os revolucionários ela era a demonstração última do colapso do Capitalismo (Niess, 2013, p.432). Os desdobramentos das greves iniciadas ainda durante o conflito mundial e da Revolução de Novembro acabam se enquadrando em uma mesma lógica discursiva, que não apenas gerará a teoria da facada pelas costas, mas a tolerará mesmo entre múltiplos campos da esquerda. A historiografia irá pavimentar, em boa medida, esse caminho, com produções como a de Eduard Berstein (1921), que inaugura esse ciclo.

Não demoraria muito para visões mais complexas virem a público, como a proposta por Arthur Rosenberg (1928). Voltado para uma análise mais abrangente, focada no preâmbulo da República de Weimar, a violência dos momentos decisivos entre a derrocada da monarquia e a ascensão de uma república essencialmente burguesa não estavam na ação espartaquista, mas na incapacidade da maioria social-democrata do Reichstag em intermediar de forma estável os anseios populares com os desdobramentos políticos. Nas palavras de Rosenberg, apesar de ter dado fim à guerra e tirado o controle político das mãos dos militares, essa elite havia perdido completamente seu contato com as massas e suas ambições:

O real significado dessa revolução pacífica nunca alcançou as massas. [No final de 1918] Eles estavam se vingando pelo fato de a maioria do Reichstag não ter alcançado essas mudanças através da luta, mas tê-las recebido como dádivas vindas de cima. Se uma grande batalha sobre a mudança constitucional tivesse ocor- 
rido publicamente durante meses, os trabalhadores e a classe média teriam tomado partido sobre isso e a teriam sentido como uma vitória deles próprios. Em 1918, à repentina vitória completa da democracia de classe média alemã seguiram-se 9 meses de um silêncio político mortal. Para que houvesse fé no novo sistema político, as massas teriam de vê-lo funcionando. O homem das ruas não conseguia compreender a mudança. (Rosenberg, 1928, p.255, trad. nossa)

Dessa forma, a revolução compreenderia não apenas os espartaquistas, mas uma gama de facções que abrangiam até mesmo social-democratas. A repressão teria sido um movimento contra "si mesmos", o resultado da incapacidade da elite política, social-democrata em especial, em conduzir o processo em direção à República. Segue-se, assim, uma narrativa apoteótica, na qual a ordem (burguesa) saiu triunfante frente à desestabilização provocada pelos ignorantes e românticos idealistas.

Mas quando interpretações mais refinadas começam a surgir, o mito da punhalada já estava consolidado no imaginário nacional alemão e já sofria modificações e adaptações para servir a determinados discursos partidários, racistas, conservadores e nacionalistas, tornando-se peça de propaganda corrente e eficaz. Pouco adiantou quando, em 1929, a interpretação de Friedrich Meinecke sobre a questão da punhalada pelas costas foi apresentada em seu texto sobre a Revolução Alemã como

uma caricatura tendenciosa do decurso dos fatos com um grãozinho de verdade ... A agitação revolucionária, que hoje ninguém mais nega, só foi historicamente eficaz quando a crença na autoafirmação vitoriosa desmoronou entre o povo desgastado e o exército, quando desapareceu a imunidade do corpo contra o veneno. (Meinecke, 1979, p.669)

A década seguinte viu a ascensão dos nazistas ao poder, e com eles o triunfo (temporário) do discurso sobre os "criminosos de novembro". A paranoia se convertia finalmente em "historiografia" sob as balizas da ditadura hitlerista, pavimentada por uma apreensão ideológica e emocional daquele contexto. $\mathrm{O}$ medo, a ansiedade, a frustração e a raiva foram sentimentos perenes na sociedade alemã nesse período, e fomentaram a busca por uma racionalização, ainda que ilógica, que explicasse aquela nova realidade.

É no complô, na conspiração, na imagem do conchavo e da traição que se encontrará a chave para essa explicação. A narrativa da punhalada pelas costas, mais que um bode expiatório, é uma denúncia de caráter político propagada, em primeiro lugar, pelo Estado Maior do Exército, tanto nas figuras privadas 
dos generais Ludendorff e Hindenburg quanto na condição de instituição do Exército. Na prestação de contas que o Alto Comando de Guerra teve de apresentar, em 1919, à Comissão de Investigação da Assembleia Nacional, a teoria da punhalada é nominalmente citada, atribuindo a culpa da derrota principalmente às instituições partidárias, que, seguindo seus interesses próprios de enfraquecimento do Estado alemão, teriam minado, com suas ações escusas na retaguarda, todos os esforços das lideranças militares no front. Afinal, os alemães, ainda que exaustos, estavam no interior da França, venciam a guerra. O Exército Alemão, concluía a declaração, fora apunhalado pelas costas. ${ }^{8}$

A natureza da narrativa do complô, como é o caso da teoria da punhalada, permite que os imensos vazios de sua argumentação sejam preenchidos por qualquer elemento que se mostre minimamente apto a fazer parte dessa narrativa. Tendo como principais pontos o domínio dos conspiradores, uma nova ordem a ser estabelecida e a sujeição da boa e inocente população que dorme sem saber da existência da conspiração, essa estrutura narrativa incorpora toda pista e todo indício que possa, de alguma forma, sustentar a sua matriz imaginária. A mitologia que se tece em volta da narrativa conspiracionista junta diferentes atores, diferentes instituições e diferentes tempos históricos para formatar uma nova história, uma história que dará sentido àquilo que a própria história não consegue explicar. A paranoia individual é a mãe da teoria da conspiração, e a paranoia coletiva, sua filha mais dileta. A chave da história não está mais nos acontecimentos públicos; isso seria o resultado superficial da encenação no teatro do mundo. As decisões reais, as origens reais da história estariam nas sombras, nos bastidores e nas sociedades secretas (Taguieff, 2004, p.133).

Dessa forma, denunciadores do complô não precisam se comprometer com a verdade ou com os fatos, uma vez que a natureza da conspiração é o segredo. As finas linhas de união de suas denúncias estão ligadas por uma lógica própria, pois está baseada e comprometida apenas com uma imagem preconcebida e com um resultado previamente gestado. Mas essa imagem, configurada e justificada na mente do teórico conspiracionista, não deixa de ter seu impacto no real. De fato, ela encontra recepção social por ir ao encontro de um anseio, aquele de compreender os engendramentos do mundo do poder, da explicação para o estado das coisas, para o alívio da realidade que, por vezes, parece não nos dar mais do que a imprevisibilidade e os acidentes da história (Girardet, 1986, p.33ss). O mito da conspiração dá ordem a esse mundo de difícil apreensão, às mudanças que parecem ainda mais ilógicas e de compreensão muito mais difícil do que as narrativas conspiracionistas, e se encaixa na 
sanha paranoica. Daí a profusão de teorias que surgem no século XIX, século da modernização, da industrialização, da quebra de paradigmas científicos e políticos, um mundo que não para de girar e que tem na Primeira Guerra Mundial o ápice da vertigem. Não é de estranhar que os illuminati, os jesuítas, os judeus e maçons ocupem espaço tão grande nesse imaginário, envolto em reuniões secretas e rituais. E não é de estranhar também que, no país onde o baque da guerra foi mais sentido, essa dinâmica imaginária tenha assumido lugar central.

Ao defenderem a ideia de uma ação conspiratória para derrotar a Alemanha na guerra e para derrubar o governo imperial, os teóricos da teoria da punhalada não deixavam de se reportar a esse imaginário. A imagem do complô já era um elemento presente na cultura alemã desde meados do século XIX, quando os romances e brochuras de conspiração ganharam o público com narrativas como Biarritz (Retcliffe, 1882), o mais famoso deles, publicado em 1868. Nele, uma conspiração mundial dos judeus é denunciada em uma cena que se passa no cemitério de Praga. Ali um grão-mestre judeu faz um discurso que explica a todos os membros dessa conspiração, representantes das 12 tribos de Israel, as formas pelas quais os judeus deveriam agir para chegar ao controle do mundo. Tal narrativa ganha vida própria e passa a ser difundida em outros escritos, que se apropriam de sua estrutura para denunciar o perigo da conspiração mundial judaica.

O caso mais famoso de apropriação da narrativa é a produção, na Rússia czarista, dos Protocolos dos Sábios de Sião, tidos por décadas como um documento real. E, mais importante ainda para o nosso caso de análise, não é nenhum acidente que a primeira tradução alemã dos Protocolos tenha sido publicada em 1919, ${ }^{9}$ momento de desenvolvimento da teoria da punhalada como verdadeira questão nacional, chegando a vender cerca de 120 mil exemplares em 2 anos (Cohn, 1967, p.141). O Antissemitismo estava, mais do que nunca, em foco naquele pós-guerra.

O Antissemitismo não era uma novidade no campo político, mas vinha se mantendo essencialmente focado nos planos econômico, religioso e social. $\mathrm{O}$ judeu era percebido como um elemento diferenciado na sociedade, muitas vezes, na expressão de Hannah Arendt, como o "judeu-excepcional" (Arendt, 2000, p.86-87), não apenas pela velha imagem arquetípica do judeu endinheirado, comerciante ou bancário, fruto de um imaginário que remonta à Idade Média e que se reforça com a instituição dos Estados nacionais. Era visto, também, como a exceção social, traduzida por uma percepção dos párias que se recusavam a se integrar pela conversão à sociedade cristã, capitalista e 
nacional, bem como a exceção educacional, representada pelos artistas, cientistas e filósofos que se destacavam por suas capacidades, mas que não gozavam da mesma proteção e incentivo governamentais de que gozavam os judeus ricos. Evidencia-se, assim, a ruptura daquele grupo social percebido de forma tão una e sólida por aqueles de fora. A exceção dos comerciantes e banqueiros não carrega consigo as exceções religiosa e educacional, e, para sobreviverem, os judeus "menos afortunados" precisam frequentemente se converter ao Cristianismo para driblar o preconceito dos gentios. O apelo das teorias internacionalistas, em especial o Comunismo e a Social-Democracia, entre esse grupo educado e ainda pária, torna-se dessa forma mais explicável.

Essa percepção do judeu como um elemento diferenciado da sociedade, como uma exceção, entretanto, ganha novo impulso na Alemanha e na Áustria no final do século XIX e nos primeiros anos do século XX. Aqui, o Antissemitismo chulo e baixo continua a fervilhar em uma base popular, florescendo o preconceito e o racismo na imprensa de caráter völkisch (e aqui podemos pensar mesmo na descrição de Hitler [2001, p.21] da Viena de sua juventude). Mas ao mesmo tempo os judeus intelectuais e artistas começam a adquirir uma reputação de destaque, juntando-se aos comerciantes e banqueiros na aceitação das elites. Reconhecidos como membros de uma "boa sociedade de classe média judia” (Gay, 2002, p.25ss), esses intelectuais recebem das elites distinção e apoio. De fato, o que se verifica é um fenômeno interessante, no qual os judeus cultos passam a se reconhecer também como exceções e, assim, a perceber a discriminação antissemita generalizada como um fenômeno social "normal".

Ao se conformarem com uma sociedade que tomava atitudes discriminatórias contra os judeus "comuns" e na qual, ao mesmo tempo, era geralmente mais fácil a círculos elegantes admitirem um judeu culto do que um não judeu de condição semelhante, os judeus tinham de se diferenciar claramente tanto do "judeu em geral" quanto, de modo igualmente claro, mostrar que eram judeus ... isso os levava à consciência de serem diferentes dos outros homens "na rua", porque eram judeus, e de serem diferentes dos outros judeus "em casa", porque não eram como os “judeus comuns". (Arendt, 2000, p.88)

Essa nova distinção não tira dos judeus a pecha de outsiders, pelo contrário. Sua aceitação nos círculos das elites reforça essa separação entre um mundo gentio e um mundo judeu, uma vez que é por sua especificidade judia que essa camada culta é aceita, e sua integração se dá pelo reforço dessa diferença. 
Pode-se dizer mesmo que é o "exotismo" de sua origem, de suas ideias e de sua produção que garante ao judeu essa entrada no teatro das elites, mas ele entra e se posiciona imediatamente no palco, sob os holofotes, sendo apontado e destacado. Todo esse processo garante uma permanente diferenciação, que ganha contornos culturais e raciais naquele século. É uma especificidade judaica que se coloca em destaque, um modo diferente de ver o mundo, e não demora para que essa Judentum venha a ser confrontada com a Deutschtum, a especificidade de ser alemão, a germanidade.

A diferenciação entre arianos e judeus se dá agora de diversas formas. Para começar, no plano racial visual, em que as grosseiras generalizações e caracterizações tipológicas garantem a qualquer um o "reconhecimento" de um judeu na rua, pela observação de um "nariz em forma de seis", de "orelhas de abano" e "pés chatos". ${ }^{10}$ Também no plano religioso, no qual o Judaísmo é não só a religião dos assassinos de Cristo, mas também uma religião materialista e capitalista; ou ainda no plano cultural, em que os judeus demonstram afinidade peculiar com as artes e as ciências, mas ao mesmo tempo exótica, formatando uma visão de mundo que não se confunde com as visões nacionais germânicas. Diante de tantas diferenças, não admira que os primeiros apontamentos de um antissemitismo político na Alemanha e na Áustria falassem de um Estado dentro do Estado, de uma Nação dentro da Nação. Trata-se de uma transposição de um imaginário já existente, que apelava para as diferenças religiosas e o sucesso econômico de pequena parcela da comunidade judaica, para denunciar uma rede de intrigas, uma conspiração que viria de tempos imemoriais e que objetivaria o domínio econômico do mundo. ${ }^{11}$

Essa aura conspirativa que passa a acompanhar a imagem dos judeus no fin-de-siècle já rende frutos nos primeiros anos do século XX. Já ali é possível observar o desenvolvimento daquilo que Pierre-André Taguieff (2004, p.137) chama de sistema de equivalências na lida com a imagem do judeu em alguns círculos sociais, especialmente naqueles definidos como racistas, völkisch nacionalistas e mesmo católicos. Nesses grupos, a estigmatização dos judeus é promovida em torno de denominações e conceitualizações duais diversas, como a ideia do "perigo judeu-maçônico", do "complô transnacional sionista", do "complô judeu-bolchevista” ou ainda "judeu-capitalista”. O judeu está assim em toda parte. A excepcionalidade dos judeus, percebida como uma vantagem em alguns círculos, é tomada em outros como um vício, uma falha moral e cultural que os levaria a assumir qualquer expressão que lhes fosse favorável. Na política, o judeu não teria uma feição clara, mas sua busca pelo poder mundial passaria pelo enfraquecimento dos Estados Nacionais, por um 
lado, e pelas ideologias internacionalistas, por outro. O judeu entra assim, definitivamente, nas discussões políticas.

Essa protoimagem de uma vertente política para a conspiração judaica é, finalmente, desenvolvida em sua plena potencialidade após a Primeira Guerra Mundial. Mas ainda que as imagens de reuniões secretas em cemitérios abandonados, discursos conspiracionistas em meio à madrugada e os próprios Protocolos dos Sábios de Sião estivessem presentes naquele imaginário pós-guerra, provendo a sociedade com imagens de terror e de suspeita generalizada, é no plano mais palpável do político que a mitologia da conspiração encontrará um catalisador e será potencializada. Mesclam-se as imagens dos judeus exceções com as ideologias internacionalistas que os atraíam e as imagens da Revolução de Novembro. Mesclam-se as imagens dos judeus reunidos no cemitério de Praga e das Doze Tribos de Israel espalhadas pelo mundo com os judeus comunistas e social-democratas. Mescla-se, enfim, a lenda da punhalada pelas costas com a mitologia da conspiração internacional judaica.

Dessa forma, com a adição dos judeus, a teoria da punhalada pelas costas ganha dimensão temporal imemorial, uma história e um passado que não mais se localizam na curta duração, no momento das greves de 1917 e 1918, da derrota na Grande Guerra ou na Revolução de Novembro, mas a insere em uma narrativa longeva, e com isso ganha uma credibilidade própria da ancestralidade. É assim porque sempre foi. A grande diferença é que o poder econômico, sempre colocado na linha de frente quando as narrativas antissemitas entram em cena, dá lugar ao poder político. É no sistema partidário, e especialmente na Social-Democracia, que a Judeidade, a Judentum, se manifestaria nesse caso, e é lá que estaria a fonte da traição, da decadência e do caos da Alemanha de Weimar. ${ }^{12}$

A exemplo do que os judeus bolcheviques teriam feito na Rússia, os judeus comunistas e social-democratas estariam tentando promover na Alemanha a destruição do Reich, a imposição de um sistema político manipulável e a substituição dos valores tradicionais alemães por outros de natureza universal, cosmopolita e, portanto, estrangeira. A mistificação envolta nessa imagem serve também à conexão do novo e do velho mito da conspiração: não foram poucos os conspiracionistas que viram nas ações bolchevistas a manifestação moderna do discurso do cemitério de Praga e os mandamentos dos Sábios de Sião (Bieberstein, 2008, p.223). Como toda grande mudança brusca, a nova república traz o atordoamento; como toda crise, a nova república traz a ansiedade e a raiva; impregnada de medo, a nova república traz consigo a paranoia. A teoria da conspiração judaica aliada à teoria da punhalada pelas costas 
cumpre assim um papel duplo, o explicativo, por um lado, e o mobilizador, por outro. Ela explica o porquê da crise e mobiliza a população contra o inimigo comum, ela transfere as energias represadas pelo medo e as deposita na raiva.

Entre 1917 e 1933, a literatura que se ocupou do mito da punhalada e que o vinculou, com cada vez mais força, aos judeus (e, em sua cola, com os bolcheviques e os maçons), não para de crescer e ganhar adeptos. Entre alguns dos títulos mais difundidos estão $O$ pior inimigo de um alemão, do militante völkisch Fritz Bley, Maçonaria, Guerra Mundial e Paz Mundial, de Hermann Gruber, Maçonaria Mundial, Revolução Mundial, República Mundial e Maçonaria, Sionismo, Comunismo, Espartaquismo, Bolchevismo, de Friedrich Wichtl, e A Punhalada através da Judeidade, de Hoffmann-Kutschke. ${ }^{13}$ Além de livros, o tema ganhou as páginas de grande número de jornais e revistas, dentre os quais se destacam o Ludendorffs Halbmonatsschrift, um dos periódicos mais paranoicos do pós-guerra, o conservador Süddeutsche Monatshefte, e os veículos ligados ao Partido Nazista, o Völkischer Beobachter e o Der Stürmer. A punhalada acaba se tornando a metáfora preferida para a explicação da derrota na Grande Guerra (Sammet, 2003). Ao mesmo tempo, ao criar um enquadramento discursivo (Lakoff, 2009) da conspiração da punhalada e justapô-la às imagens paranoicas das conspirações e manipulações judaicas, criou-se uma arma de propaganda perfeita. Essa se adequava a todos os alvos dos conservadores, apelava ao orgulho nacional e à camaradagem dos ex-combatentes, detratava o regime democrático republicano e reforçava a centralidade do judeu como bode expiatório e como inimigo eleito da nação.

Dentre as memórias que a conjuntura em torno da Primeira Guerra Mundial produziu, muitas foram encobertas pela sua sucessora. ${ }^{14}$ Os horrores da Segunda Guerra Mundial, dos Totalitarismos e do Holocausto eclipsaram boa parte dos traumas e das paixões geradas por aquela que chegou a ser chamada de guerra para acabar com todas as guerras. Mas é também ali que encontramos os gatilhos, ou melhor, as punhaladas que disparariam as imagens e os sentimentos que norteariam o caminho rumo às câmaras de gás. Na fantasia da conspiração, nas imagens aterrorizantes do inimigo imaginário, na paranoia resultante dessas imagens, pavimentam-se caminhos bastante reais rumo ao genocídio. Günter Grass, em seu romance $O$ Tambor, apreende perfeitamente essa situação ao escrever, sobre a Alemanha das décadas de 1920 e 1930: era uma vez "todo um povo crédulo que acreditava no Papai Noel. Mas o Papai Noel era, na verdade, o homem do gás". ${ }^{15}$ 


\section{REFERÊNCIAS}

ADORNO, Theodor. Studien zum autoritären Charakter. Frankfurt am Main: Suhrkamp, 1995.

Die Freudsche Theorie und die Struktur der faschistischen Propaganda. In: ADORNO, Theodor. Kritik: Kleine Schriften zur Gesellschaft. Frankfurt am Main: Suhrkamp, 1971. p.34-66.

ALPHANDARY, Idit. Love and Worldliness in Psychoanalysis and in the World of Hannah Arendt. Philosophy Today, v.59, n.2, p.227-255, spring 2015.

ARENDT, Hannah. Origens do totalitarismo. São Paulo: Companhia das Letras, 2000. . A promessa da política. Rio de Janeiro: Difel, 2008.

BARRUEL, Augustin. Mémoires pour servir à l'histoire du Jacobinisme. 4v. London: De l'imprimerie françoise, chez P. Le Boussonier, 1797/1798.

BEEK, Goofried zur. Die Geheimnisse der Weisen von Zion. Charlottenburg: Verlag auf Vorposten, 1919.

BERNSTEIN, Eduard. Die deutsche Revolution: Ihr Ursprung, ihr Verlauf und ihr Werk. Berlin: Gesellschaft und Erziehung, 1921.

BIEBERSTEIN, Johannes R. von. Der Mythos von der Verschwörung. Wiesbaden: Marix, 2008.

BLEY, Fritz. Der schlimmste Feind! Von einem Deutschen. Leipzig: Matthes, 1917.

BOURKE, Joanna. Fear: A Cultural History. London: Virago, 2005.

CANETTI, Elias. Massa e poder. São Paulo: Companhia das Letras, 1995.

COHN, Norman. Warrant for Genocide: the Myth of the Jewish World Conspiracy and the Protocols of the Elders of Zion. London: Eyre \& Spottswoode, 1967.

ECO, Umberto. O Cemitério de Praga. Rio de Janeiro: Record, 2011.

FREUD, Sigmund. O futuro de uma ilusão, o mal-estar na civilização e outros trabalhos (1927-1931). Rio de Janeiro: Imago, 2006.

FROMM, Erich. Die Furcht vor der Freiheit. München: Dtv, 1993.

FUNKE, Hajo. Paranoia und Politik: Rechtsextremismus in der Berliner Republik. Berlin: Schiler, 2002.

GALLUS, Alexander (Org.) Die vergessene Revolution von 1918/19. Göttingen: Vandenhoeck \& Ruprecht, 2010.

GAY, Peter. O século de Schnitzler: a formação da cultura de classe média. São Paulo: Companhia das Letras, 2002.

GIRARDET, Raoul. Mythes et Mythologies politiques. Paris: Éditions du Seuil, 1986.

GOODSPEED, D. J. Ludendorff. Rio de Janeiro: Bibliex, 1968.

GRASS, Günter. Die Blechtrommel. Frankfurt am Main: Fischer, 1960.

GREBIG, Helga (Org.) Die Deutsche Revolution 1918/19: Eine Analyse. Berlin: Vorwärts, 2008. 
GRUBER, Hermann. Freimaurerei, Weltkrieg und Weltfriede. Leipzig: Braumüller, 1917.

HAFFNER, Sebastian. Die verratene Revolution. Bern: Scherz, 1968.

HIBBING, John; SMITH, Kevin; ALFORD, John. Differences in Negativity Bias underlie Variations in Political Ideology. Behavioral and Brain Sciences, Cambridge, v.37, n.3, p.297-350, 2014.

HIRSCHFELD, Gerhard. Der Erste Weltkrieg in der deutschen und internationalen Geschichtsschreibung. Aus Politik und Zeitgeschichte, Frankfurt, 8 jul. 2004.

HITLER, Adolf. Minha luta. São Paulo: Centauro, 2001.

HOFFMANN-KUTSCHKE, Arthur. Dolchstoss durch Judentum. Berlin: s.n., 1922.

JONES, Mark. Am Anfang war Gewalt. München: Propyläen, 2017.

KERSHAW, Ian. Der NS-Staat. Hamburg: Nikol, 2009.

KLEIN, Melanie. Nosso mundo adulto e suas raízes na infância. In: Obras completas. Rio de Janeiro: Imago, 1997. v.3, p.281-297.

. The Psycho-Analysis of Children. New York: Grove, 1960.

KRISTEVA, Julia. El Genio Femenino: La vida, la locura, las palabras: Melanie Klein. Buenos Aires: Paidós, 2001.

KROVOZA, Alfred. Politische Psychologie. In: LOHMANN, Hans-Martin; PFEIFFER, Joachim (Org.) Freud-Handbuch: Leben-Werk-Wirkung. Stuttgart: Metzler, 2013. p.423-429.

KUTTNER, Erich. Der Sieg war zum Greifen nahe: unwiderlegliche Zeugnisse gegen die Lüge vom Dolchstoss. Berlin: Verlag für Sozialwissenschaft, 1924.

LAKOFF, George. The Political Mind. New York: Penguin, 2009.

LIEBEL, Vinícius. Confrontação e cordialidade: elementos para uma comparação entre os pensamentos autoritários de Carl Schmitt e Francisco Campos. Oficina do Historiador, Porto Alegre: Edipucrs, v.8, n.2, p.120-136, jul./dez. 2015.

. Politische Karikaturen und die Grenzen des Humors und der Gewalt: eine dokumentarische Analyse der nationalsozialistischen Zeitung "Der Stürmer". Opladen: Budrich UniPress, 2011.

LODGE, Milton; TABER, Charles. The Rationalizing Voter. Cambridge: Cambridge University Press, 2013.

LUDENDORFF, Erich. Der totale Krieg. München: Ludendorff, 1936.

MEINECKE, Friedrich. Die Deutsche November-Revolution: Ursachen und Tatsachen. In: . Brandenburg, Preussen, Deutschland: Kleine Schriften zur Geschichte und Politik. Stuttgart: Koehler, 1979. p.648-681.

MOUFFE, Chantal. On the Political. London \& New York: Routledge, 2005.

NEBELIN, Manfred. Ludendorff: Diktator im Ersten Weltkrieg. München: Siedler, 2010.

NIESS, Wolfgang. Die Revolution von 1918/1919 in der deutschen Geschichtsschreibung. Oldenbourg: de Gruyter, 2013. 
NIESS, Wolfgang. Die Revolution von 1918/1919: Der wahre Beginn unserer Demokratie. Berlin: Europa, 2017.

NIETZSCHE, Friedrich. Além do bem e do mal. São Paulo: Companhia das Letras, 2005.

OFFENSTADT, Nicolas. La Grande Guerre. In: DOSSE, François et al. (Org.) Historiographies: Concepts et Débats. Paris: Gallimard, 2010. p.1062-1074.

PARGE, Martina. Holocaust und autoritärer Charakter: Amerikanische Studien der vierziger Jahre vor dem Hintergrund der 'Goldhagen-Debatte'. Wiesbaden: DUV, 1997.

PHILLIPS, John. The Fissure of Authority: Violence and the Acquisition of Knowledge. In: STONEBRIDGE, Lyndsey; . (Ed.) Reading Melanie Klein. London \& New York: Routledge, 1998.

REICH, Wilhelm. Massenpsychologie des Faschismus. Köln: KiWi, 1973.

RETCLIFFE, John. Biarritz: historisch-politische Romane. Berlin: Kogge \& Fritze, 1882.

ROCHA, Graciliano. Para CIA, paranoia excessiva de militares resultou no AI-5. Folha de S. Paulo. São Paulo, 14 jan. 2016. Disponível em: http://www1.folha.uol.com.br/ poder/2016/01/1729294-para-cia-paranoia-excessiva-de-militares-resultou-no-ai-5.shtml; Acesso em: 1 mar. 2016.

ROSENBERG, Arthur. Die Entstehung der deutschen Republik (1871-1918). Berlin: Rohwolt, 1928.

SAMMET, Rainer. Dolchstoss: Deutschland und die Auseinandersetzung mit der Niederlage im Ersten Weltkrieg (1918-1933). Berlin: Trato, 2003.

SCHEIDEMANN, Phillip. Memoiren eines Sozialdemokraten. Dresden: Reissner, 1928.

SCHMITT, Carl. O conceito do político/Teoria do partisan. Belo Horizonte: Del Rey, 2008.

SCHULZ, Gerhard. Revolutionen und Friedensschlüsse 1917-1920. München: DTV, 1969.

SEGELKE, Arne. The Memorialization of 9 November 1918 in the Two German States. In: NIVEN, Bill; PAVER, Chloe (Org.) Memorialization in Germany since 1945. Basingstoke: Palgrave, 2010. p.369-378.

SHAKESPEARE, William. Otelo - o mouro de Veneza. São Paulo: Nova Fronteira, 2014.

STERNSDORF-HAUCK, Christiane. Brotmarken und rote Fahnen: Frauen in der bayrischen Revolution und Räterepublik. Karlsruhe: Neuer isp, 2008.

TAGUIEFF, Pierre-André. Les Protocoles des Sages de Sion: faux et usages d'un faux. Paris: Berg International-Fayard, 2004.

WEIL, Simone. On the Abolition of all Political Parties. New York: NYRB, 2014.

WICHTL, Friedrich. Freimaurerei, Zionismus, Kommunismus, Spartakismus, Bolschewismus. Hamburg: s.n., 1921. 
WICHTL, Friedrich. Weltfreimaurerei, Weltrevolution, Weltrepublik. München: Lehmann, 1923.

WINTER, Jay; PROST, Antoine. The Great War in History. Cambridge: Cambridge University Press, 2005.

ZOJA, Luigi. Paranoia: la locura que hace la historia. Buenos Aires: Fondo de Cultura Económica, 2013.

\section{NOTAS}

${ }^{1} \mathrm{O}$ campo historiográfico contemporâneo já não é o mesmo daquele da década de 1980, mas pode ser prudente fazer uma breve nota sobre o uso da Psicanálise e suas teorias como elementos de apoio ao historiador em suas análises. Já não vivemos um tempo em que os historiadores, como descrito então por Peter Gay, "procuram refugiar-se numa hipocrisia deliberadamente cultivada, e ostentar a sua ignorância como um símbolo de sabedoria profissional" (GAY, 1987, p.27). Reforçamos aqui o uso das reflexões psicanalíticas como elemento de suporte, e de forma alguma determinista ou universal - o que costuma ser a grande crítica dos historiadores. As especificidades próprias dos objetos historiográficos precisam ser respeitadas, e as estruturas e dinâmicas mentais (individuais e coletivas) apresentadas pelos psicanalistas servem à reflexão do historiador, mas não as engessam em sua estrutura. Sobre esse aspecto, o mesmo Peter Gay afirmou que "Freud pretendeu ter descoberto os determinantes psicológicos gerais; enquanto cientista da mente não poderia aspirar a menos. Mas, como nos advertiu em Civilization and its discontents, qualquer generalização coloca o pesquisador 'em perigo de esquecer a coloração multivariada - Buntheit - do mundo humano e de sua vida mental'. Um historiador não poderia ter dito melhor" (GAY, 1987, p.40).

No que tange aos estudos sobre o nazismo, as críticas recaem, em geral, sobre seu caráter estrutural e globalizante, por um lado, ou em seu determinismo individual, por outro. Estudos pioneiros, como os de Wilhelm Reich e Erich Fromm, lançaram luzes pertinentes sobre o fenômeno político e ideológico de massas do nazifascismo, assim como os escritos da Teoria Crítica demonstraram refinamento no uso da Psicanálise como ferramenta auxiliar. Em que pesem tais contribuições, o próprio Adorno aponta que uma compreensão total do fenômeno do nazismo seria impossível com base apenas na Psicanálise (1971). Alguns críticos de peso foram ainda mais incisivos, como Hannah Arendt (2008) - ela julgava que a Psicanálise, ao se centrar no mundo do indivíduo e das sensações, direciona-nos para a perda da mediação intersubjetiva, a essência de sua teoria da ação política. Isso nos guiaria, por um lado, ao esquecimento e naturalização de fenômenos como o nazismo e, por outro, nos levaria ao conformismo que acaba com a possibilidade revolucionária de mudança no mundo (ALPHANDARY, 2015, p.228); ou KERSHAW (2009, p.54), o qual argumenta que as interpretações psicanalíticas falham em apresentar uma metodologia fechada e coerente que possibilite o desenvolvimento de estudos nessa linha. A Psicanálise, por certo, não apresenta as credenciais para explicações reducionistas ou totalizantes do nazismo, mas abre caminho para reflexões que possibilitam uma redimensionalização 
do saber histórico e a apreensão de novas perspectivas, em uma construção transdisciplinar sobre as fronteiras da Psicologia cultural e política, da História Cultural do Político e da Teoria da Cultura (KROVOZA, 2013, p.424). É nesse sentido que lançamos mão dela neste ensaio.

${ }^{2}$ Adversários, não inimigos, como na clássica proposição de SCHMITT (2008). Ver também LIEBEL, 2015.

${ }^{3}$ Conjuração que teria sido levada a cabo pela "classe dos filósofos”, esboçada desde o movimento do Iluminismo, visando à quebra da ordem monárquica e à destruição da religião (BIEBERSTEIN, 2008, p.37ss).

${ }^{4}$ Não significa, claro, que no campo dito progressista não exista a possibilidade da paranoia. A construção de inimigos e de ameaças (ao poder, à posição dentro do partido etc.) pode também se apresentar no campo da "esquerda". Para o presente, entretanto, é o campo conservador e da "direita" que será considerado.

${ }^{5}$ Conjunto de ideias e ditames que voltava todas as esferas do Estado beligerante para os esforços de guerra. Ver LUDENDORFF, 1936.

${ }^{6}$ Uma das primeiras indagações ocorre ainda em 1924 e se centra no questionamento da identidade e da possibilidade de encontro entre Ludendorff e o general Frederick Barton Maurice (KUTTNER, 1924). Ainda que o nome de Maurice tenha sido largamente utilizado no período, recai sobre o general Malcom a maior probabilidade do encontro, uma vez que este estava, afinal, em Berlim no pós-guerra.

${ }^{7}$ Para uma discussão mais aprofundada sobre a historiografia da Grande Guerra, ver OFFENSTADT, 2010; WINTER; PROST, 2005; HIRSCHFELD, 2004.

8 "Ein englischer General sagt mit Recht: die deutsche Armee ist von hinter erdolcht worden." In: Erklärung Hindenburgs und Ludendorffs abgegeben am 18. November 1919 vor dem Untersuchungsauschuss der Nationalversammlung. p.5.

${ }^{9}$ Trata-se de BEEK, 1919.

${ }^{10}$ Para uma reconstrução dessa trajetória iconográfica do "inimigo judeu”, ver LIPTON, 2014 e LIEBEL, 2011.

${ }^{11}$ Essas teorias são também um reflexo de uma visualidade "ameaçadora", ou seja, elas seriam apoiadas no número de judeus que viviam em Viena, por exemplo, no início do século XX. Antes de 1938 (Anschluss/plebiscito), a comunidade judaica vienense era uma das maiores da Europa, com cerca de 120 mil pessoas (de uma população total de 1,5 milhão) - sendo metade dos 4 mil médicos, e cerca de 650 dos mil advogados; depois da Guerra, uma diminuta quantidade de judeus voltou a se estabelecer na cidade, que hoje conta com cerca de 10 a 12 mil judeus (GAY, 2002).

${ }^{12}$ A ampliação da estrutura da metáfora a tornou, a um só tempo, mais incisiva e mais maleável. Os conceitos e adjetivos para denominá-lo eram bastante variáveis, e, como demonstra NIESS (2013, p.133), até mesmo a metáfora da punhalada podia ser deixada de lado em alguns casos. Mais relevante para a "historiografia nazista" era a ênfase sobre o 
papel dos judeus como organizadores secretos de toda agitação e revolta. Para o nazismo no poder, a punhalada já não tinha a relevância central que podia ter na propaganda de agitação, mas o elemento paranoico da organização secreta por parte dos judeus continuava relevante e ativo.

${ }^{13}$ BLEY, 1917; GRUBER, 1917; WICHTL, 1921; 1923; HOFFMAN-KUTSCHKE, 1922.

${ }^{14}$ A continuidade da temática das greves e da revolução na historiografia alemã do pós-guerra está intimamente ligada aos caminhos que o país percorreu, sendo tais eventos percebidos ora como nascimento da democracia alemã (linha majoritária na RFA), com suas contradições ideológico-partidárias (ver HAFFNER, 1968), ora como demonstração de uma consciência revolucionária de classes que antecederia a fundação da República Democrática da Alemanha (linha predominante na própria RDA), com suas experiências e organizações em conselhos (ver SEGELKE, 2010). Mas ainda que fosse percebido como um ponto nevrálgico na história alemã, os estudos acadêmicos sobre aquele contexto foram, após a queda do Muro de Berlim, relegados a um silêncio gritante, como se, na expressão de Alexander Gallus (2010), fosse uma revolução esquecida. As poucas obras que surgem pouco contribuíram para a modificação do quadro, com as exceções do livro organizado por GREBIG (2008), do estudo do papel das mulheres nas greves e na revolução por STERNSDORF-HAUCK (2008), do livro organizado por GALLUS (2010), com novos apontamentos e perspectivas de pesquisa sobre a temática e do volume de JONES (2017) sobre o lugar da violência e da repressão na legitimação do novo Estado republicano, além das duas obras de NIESS $(2013 ; 2017)$, sobre a historiografia e a memória acerca dos eventos.

15 "Ein ganzes leichtgläubiges Volk glaubte an den Weihnachtsmann. Aber der Weihnachtsmann war in Wirklichkeit der Gasmann” (GRASS, 1960, p.261).

Artigo recebido em 26 de abril de 2017. Aprovado em 18 de setembro de 2017. 